\title{
Phosphorylated 4E-BP1 is associated with tumor progression and adverse prognosis in colorectal cancer
}

\author{
Y. CHEN, J. WANG, H. FAN, J. XIE, L. XU, B. ZHOU* \\ Department of Hepatobiliary Surgery, The Second Affiliated Hospital of Wenzhou Medical University, Wenzhou, 325000, China \\ *Correspondence: zhoubin20051081@sina.com
}

Received November 17, 2016 / Accepted February 25, 2017

\begin{abstract}
Phosphorylation of eukaryotic translation initiation factor 4E (eIF4E)- binding protein (4E-BP1) results in release of eIF4E, relieving translational repression and enhancing cancerigenic protein synthesis. This study aim to evaluate the level of phosphorylated 4E-BP1 (p-4E-BP1) in colorectal cancer (CRC) and to assess the correlation with clinicopathological factors and patient survival. The level of $\mathrm{p}-4 \mathrm{E}-\mathrm{BP} 1$ was detected by immunohistochemistry and western bolt in patients with CRC. Then Cox regression model was used to evaluate the prognostic value of all covariates. Among 164 assessed patients, $95(57.9 \%)$ patients showed high level of p-4E-BP1. We noted that the level of p-4E-BP1 was significantly associated with tumor differentiation, invasive depth, lymph node metastasis and TNM stage. Then we compared the mRNA and protein expressions of $4 \mathrm{E}-\mathrm{BP} 1$ in tumor regions and paired adjacent normal colorectal mucosal tissues in CRC patients. mRNA and protein expressions of 4E-BP1 did not differ between colorectal cancer and corresponding normal tissues, while the phosphorylation level of 4E-BP1 was markedly increased in CRC. Survival analysis and Cox proportional hazards model revealed that $\mathrm{p}-4 \mathrm{E}-\mathrm{BP} 1$ was an independent adverse prognostic factor for both overall survival (OS) $(\mathrm{HR}=5.414, \mathrm{p}=0.029)$ and progression-free survival (PFS) $(\mathrm{HR}=4.754, \mathrm{p}=0.042)$. Herein, our results indicate that high $\mathrm{p}-4 \mathrm{E}-\mathrm{BP} 1$ level is associated with tumor progression and adverse prognosis. p-4E-BP1 might be a novel biomarker to predict the clinical outcome of patients with CRC.
\end{abstract}

Key words: colorectal cancer, $p-4 E-B P 1$, biomarker, tumor progression, prognosis

Colorectal cancer (CRC) is both the third most common cancer incidence and cancer death in global [1]. Although death rate is decreasing over the past several decades owing to screening programs and therapy more than 1.2 million patients are diagnosed with CRC and more than 600,000 patients die from the this disease yearly [2]. Currently, the keystone treatment for CRC is surgery for stage I cases, with adjuvant radiotherapy and systemic chemotherapy for stages II and III. In addition to traditional chemotherapy drugs, several targeted monoclonal antibodies such as bevacizumab, cetuximab, panitumumab, and capecitabine have been applied in the clinic [3]. However, the treatment of CRC is still far from ideal $[4,5]$. Therefore, the development of prognostic and predictive biomarkers is eagerly awaited for the targeted therapeutics of CRC.

The activation of cell signaling pathways associated with cell growth and proliferation plays a critical role in human tumors [6]. In recent years, several biomarkers involved in cancer progression and clinical outcome have been used in a number of tumors and became potential therapeutic targets, including eukaryotic translation initiation factor 4E (eIF4E)binding protein (4E-BP1). 4E-BP1 is one of downstream molecules that receive convergent signals from several intracellular signal pathways, including phosphatidylinositol-3 kinase $(\mathrm{PI} 3 \mathrm{~K}) /$ protein kinase $\mathrm{B}(\mathrm{AKT}) /$ mammalian target of rapamycin (mTOR) and RAS/mitogen-activated protein kinase (MAPK). Above PI3K/AKT/mTOR and RAS/MAPK pathway play a key role in transmitting the proliferative signal from the membrane receptors to the nucleus and driving cell proliferation $[7,8]$. 4E-BP1 is phosphorylated by AKT and MAPK and then exerts effects on RNA translation and cell growth regulation $[9,10]$. The role of $\mathrm{p}-4 \mathrm{E}-\mathrm{BP} 1$ in cancer initiation and progression makes it a promising candidate tumor biomarker. Recently, several studies have been reported that high level of $\mathrm{p}-4 \mathrm{E}-\mathrm{BP} 1$ correlates with aggressive pathologic grade and adverse prognosis in a variety of malignancies 
including esophageal squamous cell carcinoma, astrocytoma, renal cell carcinoma, hilar cholangiocarcinoma, small cell lung cancer, clear cell renal cell carcinoma and non-small cell lung cancer [11-17]. Therefore, the level of p-4E-BP1 in tumor cells might indicate its carcinogenic potential. In this study, we investigated the level of p-4E-BP1 in CRC and analyzed its association with a great deal of clinicopathological factors and patient survival.

\section{Patients and methods}

Patients and tissue samples. A total of 164 patients with CRC who underwent radical or palliative resection at the Second Affiliated Hospital of Wenzhou Medical University between 2007 and 2009 were included in this study. Neoadjuvant chemotherapy was not used before surgery in any of the cases. Fresh samples from pathologically representative tumor regions and paired adjacent normal colorectal mucosal tissues were obtained. HE-stained slides were prepared and reviewed by two pathologists to ensure the quality of tissue blocks. Patient tumor characteristics such as histological differentiation extent, location, invasive depth, lymphatic and venous invasion, were summarized. Other clinicopathological data such as sex, age, distant metastasis and survival data were obtained from medical records. Clinical stages of all CRC patients were determined according to the $7^{\text {th }}$ edition of American Joint Committee on Cancer TNM staging system [18]. Clinical follow-up was available for all the patients. Overall survival (OS) was defined as the time interval between the initiation of surgery and the date of death or last follow-up, whichever occurred first. Progression-free survival (PFS) was defined from the date of surgery to the date of disease progression or censoring at the time of last follow-up. This study was approved by the ethics committee of the Second Affiliated Hospital of Wenzhou Medical University. Written informed consent was obtained from each patient before any study-specific investigation was performed.

Immunohistochemistry. Immunohistochemistry staining was carried out using the avidin-biotin-peroxidase technique. Paraffin-embedded CRC samples were deparaffinized and then blocked in $3 \%$ hydrogen peroxide solution in absolute methanol for 10 minutes at room temperature. After heatinduced antigen retrieval in $10 \mathrm{mM}$ citrate buffer ( $\mathrm{PH}$ 6.0) $95-100^{\circ} \mathrm{C}$ for $10 \mathrm{~min}$ and blocking with $3 \% \mathrm{BSA}$, samples were incubated with the primary antibody at $4{ }^{\circ} \mathrm{C}$ overnight. The primary antibody we used was rabbit anti-phospho-4E-BP1 (Thr37/46) monoclonal antibody (\#2855, dilution 1:300) (Cell Signaling Technology, Danvers, MA, USA). Chromogenic examination was performed with a peroxidase conjugated secondary antibody (30 $\mathrm{min}$ ) and DAB reagents ( $5 \mathrm{~min}$ ) provided in the Envision detection kit (Dako, Cytomation, Glostrup, Denmark). All samples were counterstained with Mayer's Hematoxylin (Thermo Fisher Scientific, Waltham, MA, USA). Omission of the primary antibody with phosphate-buffered saline acted as the negative control.
Immunostained slides were evaluated by two experienced pathologists who were blinded to all clinical parameters, in an open discussion. For the immunoreactivity, a histoscore (H-score) based on the percentage of immunoreactive cells $(0-100 \%)$ and the intensity of immunostaining was calculated and classified into four categories (negative; weak: + ; moderate: ++ ; strong: +++ ). Tumors with no staining were classified as negative. Tumors with weak intensity $(+)$ in $<$ $33 \%$ of cells were classified as weak. Tumors with moderate intensity $(++)$ in $>66 \%$ of cells or strong intensity $(+++)$ in $>33 \%$ of cells were classified as strong. The rest tumors were classified as moderate. The tumors with the $\mathrm{H}$-score in the strong category were considered high level, while other tumors were considered low level [19].

Semi-quantitative reverse transcription polymerase chain reaction (qRT-PCR). Total RNA was extracted from the pathologically representative tumor regions $(\mathrm{T})$ and paired adjacent normal colorectal mucosal tissues $(\mathrm{N})$ of 6 patients by TRIzol' Reagent (Invitrogen Technologies, Carlsbad, CA, USA) according to the manufacturer's instruction. Single-stranded cDNA was synthesized using M-MLV reverse transcriptase (Invitrogen Technologies) from total RNA. Oligo (dT) 18 was used as the RT primers for reverse transcription of mRNAs. In the qRT-PCR, each sample was run in triplicate in a $10 \mu \mathrm{l}$ reaction with $250 \mathrm{nM}$ forward and reverse primers, $5 \mu \mathrm{l}$ of SYBR Green Supermix (Bio-Rad, Berkeley, CA, USA) and $10 \mathrm{ng}$ of cDNA. GAPDH was used as control. Reactions were performed in the BIO-RAD CFX Real-Time System and relative mRNA expression levels were calculated using the $\Delta \mathrm{Ct}$ method $\left(2^{-\Delta \Delta C t}\right)$. The primers were as follows: $4 E-B P 1$, forward 5'-GGGGACTACAGCACGAC-3' and reverse 5'-CGCCCG CTTATCTTCT-3'; GAPDH, forward 5'-GGAAGGTGAAGGTCGGAGT-3' and reverse 5'-CCTGGAAGATGGTGA TGGG-3'.

Western blot analysis. For western blot, 6 pairs of pathologically representative tumor regions and paired adjacent normal colorectal mucosal tissues were lysed with $0.5 \%$ NP40 buffer containing protease inhibitor cocktail on ice, and the supernatants were collected by centrifugation at 13,000 rpm at $4{ }^{\circ} \mathrm{C}$ for $15 \mathrm{~min}$. Protein extract was separated by $10 \%$ SDS-polyacrylamide gel electrophoresis and transferred to nitrocellulose membranes. Membranes were blocked with $5 \%$ skimmed milk and then incubated with primary antibody overnight at $4{ }^{\circ} \mathrm{C}$. The dilutions of monoclonal antibody $4 \mathrm{E}$ BP1 and phosphorylated 4E-BP1 (p-4E-BP1) (Cell Signaling Technology) were 1:1000. The line densitometry was quantified by Image J software (version 1.61, National Institutes of Health, MD, USA).

Statistical analysis. All statistical analyses were performed using SPSS software version 18.0 (SPSS Inc., Chicago, IL, USA). To evaluate relationships between clinicopathological characteristics and immunohistochemical results, we used Chi-square test for categorical variables. OS and PFS were assessed using the Kaplan-Meier method and compared by the log-rank test. The Cox proportional hazards model for 
multivariate survival analysis was used to evaluate the association between $\mathrm{p}-4 \mathrm{E}-\mathrm{BP} 1$ and survival. The criterion for statistical significance was $p<0.05$.

\section{Results}

Clinicopathological characteristics. We studied 164 colorectal cancer patients, comprising 75 males $(45.7 \%)$ and $89(54.3 \%)$ females. The median age of these patients at diagnosis was 56 years (range from 21 to 91 years). Tumor locations were $71(43.3 \%)$ in rectum, 93 (56.7\%) in colon. $146(89.0 \%)$ patients had symptoms at the time of diagnosis. Histologically, 102 tumors (62.2\%) were classified as well or moderately differentiated carcinoma, while $62(37.8 \%)$ were poorly differentiated. 90 tumors (54.9\%) were smaller than $5 \mathrm{~cm}$, whereas, 74 tumors $(45.1 \%)$ had a minimum diameter of $5 \mathrm{~cm}$ or more. Pathological T stage was pT1-2 for $75(45.7 \%)$ tumors, and pT3-4 for 89 (54.3\%). There were 88 cases $(53.7 \%)$ of lymphatic invasion and 10 cases
(6.1\%) had distant metastasis at initial diagnosis. 84 cases (51.2\%) were classified as I- II stage and 80 cases $(48.8 \%)$ as III-IV stage according to TNM staging system. These clinicopathological characteristics of the entire cohort are summarized in Table 1.

Correlation between p-4E-BP1 level and clinicopathological characteristics. The correlation between $\mathrm{p}-4 \mathrm{E}-\mathrm{BP} 1$ level detected by immunohistochemistry and clinicopathological characteristics of 164 patients with CRC are presented in Table 1 . The level of p-4E-BP1 was low in 69 tumors (42.1\%) and high in 95 tumors (57.9\%). A significant adverse correlation between $\mathrm{p}-4 \mathrm{E}-\mathrm{BP} 1$ level and tumor differentiation was observed $(p=0.023)$. In contrast, a remarkable positive association was observed between depth of invasion and p-4E-BP1 level $(p=$ 0.026 ). High level of $\mathrm{p}-4 \mathrm{E}-\mathrm{BP} 1$ occurred more frequently in tumors with regional lymph nodes metastasis than that with low level $(p=0.005)$. In addition, the rate of high $\mathrm{p}-4 \mathrm{E}-\mathrm{BP} 1$ level, which was $58.9 \%$ in CRC cases with TNM stage III-IV, was decreased to $44.1 \%$ in patients with TNM stage I- II ( $p=$

Table 1. P-4E-BP1 level in relation to clinicopathological characteristics in 164 patients with colorectal cancer

\begin{tabular}{|c|c|c|c|c|}
\hline \multirow{2}{*}{ Clinicopathological factors } & \multirow{2}{*}{$\begin{array}{l}\text { Entire group } \\
\qquad(\mathrm{n}=164)\end{array}$} & \multicolumn{2}{|c|}{ p-4E-BP1 level } & \multirow{2}{*}{$p$ value } \\
\hline & & Low $(n=69)$ & High $(\mathbf{n}=95)$ & \\
\hline Age at surgery (years) & & & & 0.748 \\
\hline$<60 \mathrm{n}(\%)$ & $66(40.2 \%)$ & $29(42.0 \%)$ & $37(38.9 \%)$ & \\
\hline$\geq 60 \mathrm{n}(\%)$ & $98(59.8 \%)$ & $40(58.0 \%)$ & $58(61.0 \%)$ & \\
\hline Sex & & & & 0.751 \\
\hline Male n (\%) & $75(45.7 \%)$ & $33(47.8 \%)$ & $42(44.2 \%)$ & \\
\hline Female n (\%) & $89(54.3 \%)$ & $36(52.2 \%)$ & $53(55.8 \%)$ & \\
\hline Clinical manifestation (n, \%) & & & & 0.312 \\
\hline Incidental & $18(11.0 \%)$ & $10(14.5 \%)$ & $8(8.4 \%)$ & \\
\hline Symptomatic & $146(89.0 \%)$ & $59(85.5 \%)$ & $87(91.6 \%)$ & \\
\hline Location (n, \%) & & & & 0.342 \\
\hline Rectum & $71(43.3 \%)$ & $33(47.9 \%)$ & $38(40.0 \%)$ & \\
\hline Colon & $93(56.7 \%)$ & $36(52.2 \%)$ & $57(60.0 \%)$ & \\
\hline Differentiation & & & & 0.023 \\
\hline Well/moderately & $102(62.2 \%)$ & $50(72.5 \%)$ & $52(54.7 \%)$ & \\
\hline Poorly & $62(37.8 \%)$ & $19(27.5 \%)$ & $43(45.3 \%)$ & \\
\hline Size $(\mathrm{cm})$ & & & & 0.058 \\
\hline$<5$ & $90(54.9 \%)$ & $44(63.8 \%)$ & $46(48.4 \%)$ & \\
\hline$\geq 5$ & $74(45.1 \%)$ & $25(36.2 \%)$ & $49(51.6 \%)$ & \\
\hline Pathological T stage & & & & 0.026 \\
\hline $\mathrm{T} 1-2$ & $75(45.7 \%)$ & $39(56.5 \%)$ & $36(37.9 \%)$ & \\
\hline $\mathrm{T} 3-4$ & $89(54.3 \%)$ & $30(43.5 \%)$ & $59(62.1 \%)$ & \\
\hline Pathological N stage & & & & 0.005 \\
\hline No & $76(46.3 \%)$ & $41(59.4 \%)$ & $35(36.8 \%)$ & \\
\hline N1-2 & $88(53.7 \%)$ & $28(40.6 \%)$ & $60(63.2 \%)$ & \\
\hline Pathological M stage & & & & 0.194 \\
\hline M0 & $154(93.9 \%)$ & $67(97.1 \%)$ & $87(91.6 \%)$ & \\
\hline M1 & $10(6.1 \%)$ & $2(2.9 \%)$ & $8(8.4 \%)$ & \\
\hline TNM stage & & & & 0.005 \\
\hline I- II & $84(51.2 \%)$ & $45(65.2 \%)$ & $39(41.1 \%)$ & \\
\hline III-IV & $80(48.8 \%)$ & $24(34.8 \%)$ & $56(58.9 \%)$ & \\
\hline
\end{tabular}



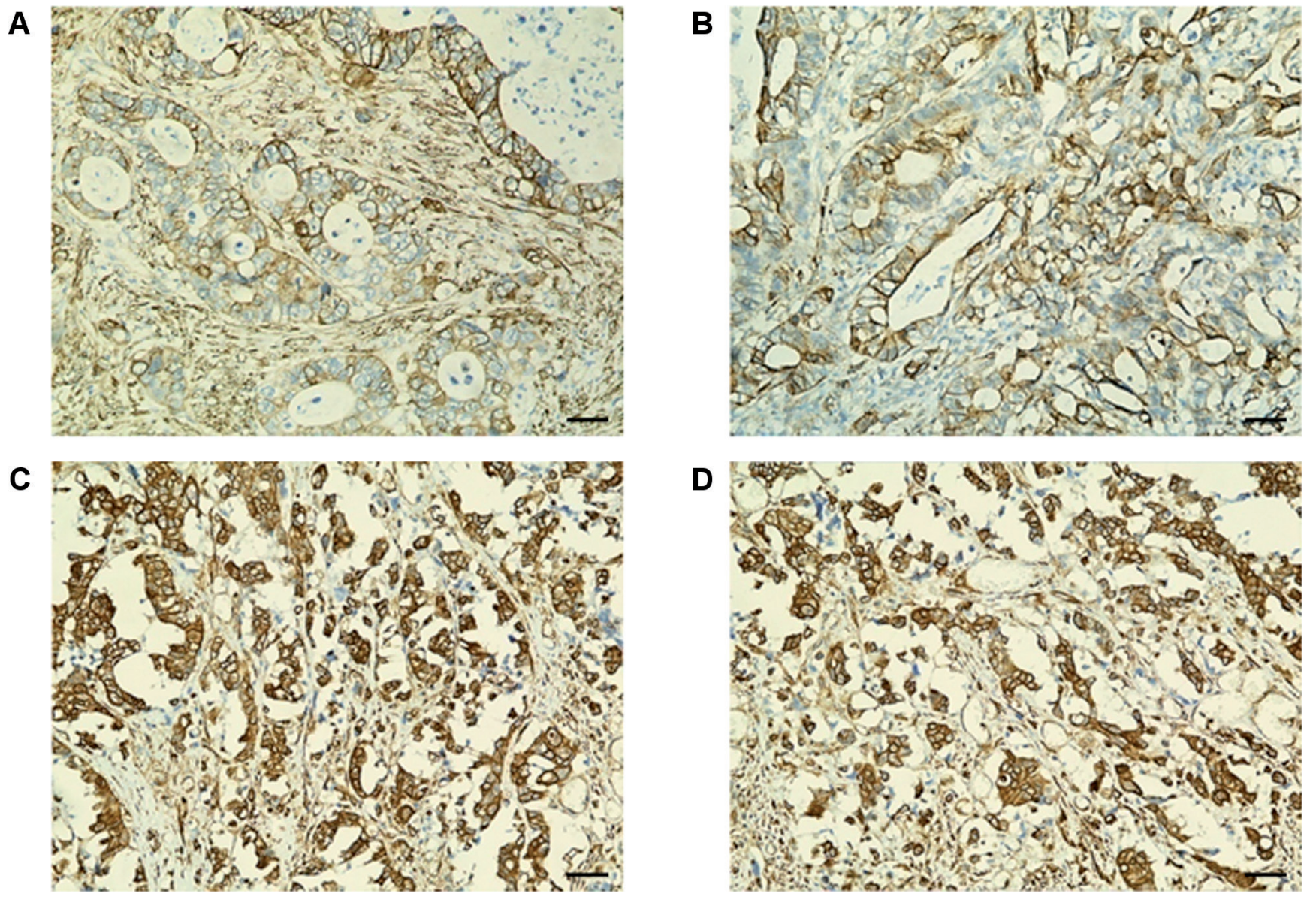

Figure 1. Representative immunohistochemical staining of p-4E-BP1 in different TNM stages of colorectal cancer. (A) Low level of p-4E-BP1 in TNM stage I; (B) Low level of p-4E-BP1 in TNM stage II; (C) High level of p-4E-BP1 in TNM stage III; (D) High level of p-4E-BP1 in TNM stage IV. Original magnification of immunohistochemical images, $\times 200$.

0.005) (Table 1 and Figure $1 \mathrm{~A}-\mathrm{D}$ ); Above result indicates p-4EBP1 level is significantly correlated with TNM stages. However, there was no significant association of p-4E-BP1 level with any other clinicopathological features including gender, age at surgery, clinical manifestation, tumor location, tumor size and pathological $\mathrm{M}$ stage.

Level of p-4E-BP1 in CRC tissues. The relative expression of $4 \mathrm{E}-\mathrm{BP} 1$ in CRC and corresponding normal tissues at the mRNA and protein level were detected by semi-quantitative RT-PCR and western blot, respectively. We found that although 4E-BP1 did not differ from tumors compared to their adjacent healthy tissues both in mRNA and protein levels (Figure 2 and $3 \mathrm{~A}$ ), the phosphorylation of $4 \mathrm{E}-\mathrm{BP} 1$, was increased to 3.1-fold in CRC compared to adjacent healthy tissues ( $p=0.021$; Figure $3 \mathrm{~A}$ and $\mathrm{B}$ ). Thus, $4 \mathrm{E}-\mathrm{BP} 1$ is hyperphosphorylated in CRC.

Relationship between p-4E-BP1 level and CRC prognosis. The Kaplan-Meier survival curves for OS and PFS according to level of p-4E-BP1 are displayed in Figure 4A and B. Survival analyses showed that $\mathrm{p}-4 \mathrm{E}-\mathrm{BP} 1$ was signifi- cantly associated with tumor progression and poor prognosis. Patients with high p-4E-BP1 level had a significantly shorter median PFS (25 months, $95 \%$ CI 14.3-27.5 months) than patients with low p-4E-BP1 level (38 months, $95 \%$ CI 27.1-48.9 months) ( $p=0.018$; Figure $4 \mathrm{~A})$. In contrast, the low $\mathrm{p}-4 \mathrm{E}-\mathrm{BP} 1$ level group had a significantly prolonged OS compared to the high level group ( $p=0.017$; Figure $4 \mathrm{~B})$.

Using the Cox proportional hazards model, we evaluated the significance of several clinicopathological factors and p-4E-BP1 level as predictors of OS and PFS with multivariate analyses. The results of Cox regression analyses for OS and PFS are depicted in Table 2. The high p-4E-BP1 level group had a significantly shorter PFS $(p=0.042)$ and OS $(p=0.029)$ compared to the low level group, indicating that the level of $\mathrm{p}-4 \mathrm{E}-\mathrm{BP} 1$ could act as an independent adverse prognostic factor of OS and PFS. Moreover, larger tumor size $(p=0.015)$, regional lymph nodes metastasis $(p=0.032)$, distant metastasis $(p=0.036)$ and later TNM stage $(p=0.028)$ were also significantly associated with worse OS of patients with CRC. Similarly, tumor differentiation $(p=0.031), \mathrm{pT}(p=0.011), \mathrm{pN}$ 


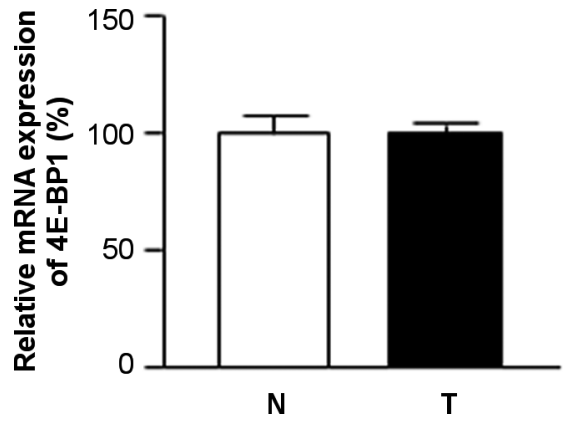

Figure 2. The expression of $4 E-B P 1$ mRNA in colorectal cancer tissues. Relative mRNA expression of $4 E-B P 1(n=6)$. T: tumor region of colorectal cancer; N: paired adjacent normal colorectal mucosal tissue.

$(p=0.014), \mathrm{pM}(p=0.001)$ and TNM stage $(p=0.041)$ were independent prognostic factors for predicting PFS.

\section{Discussion}

Considering the high probability of disease recurrence following operation for patients with CRC and poor prognosis of this disease recurrence, it is significant to identify factors that can be used to predict the precise prognosis of such postoperative patients to determine appropriate postoperative adjuvant therapy and to decide on follow-up schedules. In recent years, there have been several studies shown that an increase number of molecular markers combined with conventional clinicopathological prognostic factors were used for predictive accuracy in patients with CRC [20-22].

The present study showed that 4E-BP1 was hyperphosphorylated in CRC. And multivariate analysis in a homogeneous population of 164 patients demonstrated that the level of p-4E-BP1 was significantly associated with tumor differentiation, invasive depth, lymphatic invasion and TNM stage. High p-4E-BP1 level was observed in CRC patients with poor differentiation, regional lymph node metastasis and later TNM


Figure 3. The level of $4 \mathrm{E}-\mathrm{BP} 1$ and $\mathrm{p}-4 \mathrm{E}-\mathrm{BP} 1$ in colorectal cancer tissues. (A) Protein expressions of 4E-BP1 and p-4E-BP1; (B) Relative grey value of $\mathrm{p}-4 \mathrm{E}-\mathrm{BP} 1$ protein $(\mathrm{n}=6)$. $4 \mathrm{E}-\mathrm{BP} 1$ was used as the control for $\mathrm{p}-4 \mathrm{E}-\mathrm{BP} 1$. $\mathrm{T}$ : tumor region of colorectal cancer; $\mathrm{N}$ : paired adjacent normal colorectal mucosal tissue.

Table 2. Multivariate analysis of overall survival and progression-free survival

\begin{tabular}{|c|c|c|c|c|}
\hline \multirow{2}{*}{ Covariates } & \multicolumn{2}{|c|}{ overall survival } & \multicolumn{2}{|c|}{ progression-free survival } \\
\hline & HR (95\% CI) & $p$ value & HR (95\% CI) & $p$ value \\
\hline Age at surgery & $0.897(0.757-1.034)$ & 0.119 & $0.958(0.915-1.002)$ & 0.117 \\
\hline Sex (male vs. female) & $2.682(0.142-52.428)$ & 0.512 & $0.969(0.163-5.837)$ & 0.924 \\
\hline Clinical manifestation (incidental vs. symptomatic) & $0.662(0.042-332.749)$ & 0.923 & $0.964(0.219-4.521)$ & 0.721 \\
\hline Laterality (rectum vs. colon) & $0.778(0.071-14.673)$ & 0.828 & $0.741(0.165-3.396)$ & 0.702 \\
\hline Differentiation (poorly vs. well/moderately) & $1.343(0.513-2.736)$ & 0.069 & $6.533(1.277-9.141)$ & 0.031 \\
\hline Tumor size ( $\geq 5$ vs. $<5$ ) & $2.093(1.125-3.729)$ & 0.015 & $3.307(0.893-10.295)$ & 0.075 \\
\hline $\mathrm{T}$ stage (T3-T4 vs. T1-T2) & $10.425(0.342-356.025)$ & 0.062 & $8.691(0.667-353.158)$ & 0.011 \\
\hline N stage (N1-N2 vs. N0) & $3.998(0.325-28.242)$ & 0.032 & $6.522(1.678-16.254)$ & 0.014 \\
\hline M stage (M1 vs. M0) & $19.825(1.126-162.287)$ & 0.036 & $28.721(3.463-224.467)$ & 0.001 \\
\hline TNM stage (III-IV vs. I- II) & $6.275(0.862-93.279)$ & 0.028 & $5.021(0.628-72.357)$ & 0.041 \\
\hline p-4E-BP1 level (high vs. low) & $5.414(1.562-52.725)$ & 0.029 & $4.754(1.874-74.788)$ & 0.042 \\
\hline
\end{tabular}




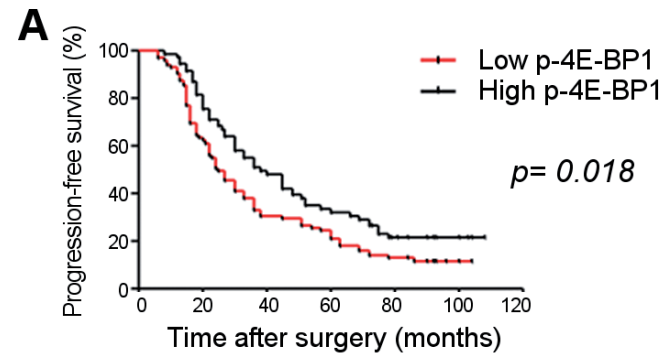

B

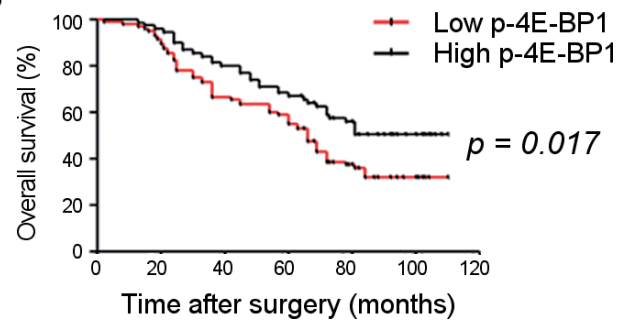

Figure 4. Kaplan-Meier analysis of PFS and OS curves in colorectal cancer patients. (A) PFS curve analysis by stratified according to p-4E-BP1 level $(\log -\operatorname{rank} p=0.018)$; (B) OS curve analysis by stratified according to $\mathrm{p}-4 \mathrm{E}-$ BP1 level $(\log -\operatorname{rank} p=0.017)$.

stage. In addition, we observed that the status of $\mathrm{p}-4 \mathrm{E}-\mathrm{BP} 1$ was an independent prognostic predictor for OS and PFS by survival analyses. The survival analyses showed that patients with high level of p-4E-BP1 were easily to recurrence and had adverse prognosis. Our results is in agreement with previous studies in esophageal squamous cell carcinoma, renal cell carcinoma, hilar cholangiocarcinoma, small cell lung cancer and non-small cell lung cancer [11, 13-16]. According to these data, we speculate that the hyperphosphorylation of $4 \mathrm{E}-\mathrm{BP} 1$ plays a positive role in CRC development. $\mathrm{p}-4 \mathrm{E}-\mathrm{BP} 1 \mathrm{might}$ be a potential tumor marker for prognostic prediction and a therapeutic target for CRC.

Growth factor receptors and cell signal pathways play crucial roles in carcinogenesis of human tumors. Activation of membrane growth factor receptors promotes cell proliferation signals via at least two major biochemical pathways, PI3K/ $\mathrm{AKT} / \mathrm{mTOR}$ and RAS/MAPK pathway $[7,8]$. The PI3K/AKT pathway classically regulates translation through activation of mTOR kinase and then phosphorylation of its substrates, 4EBP1 and S6K. The MAPK pathway, involving several biological processes (cell proliferation, survival, apoptosis and metabolism) [23], also mediates 4E-BP1 phosphorylation. Therefore, both PI3K/AKT/mTOR and RAS/MAPK pathway contribute to the phosphorylation of $4 \mathrm{E}-\mathrm{BP} 1$, which results in formation of the cap-dependent mRNA translation initiation complex $[24,25]$. During cap-dependent translation, eIF4E binds to the mRNA cap structure and promotes formation of the eIF4E initiation complex and ribosome binding. Dephosphorylated 4E-BP1 binds tightly to eIF4E and hinders the formation of the cap-dependent mRNA translation initiation complex that involves in protein synthesis. Thus, $4 \mathrm{E}-\mathrm{BP} 1$ negatively regulates protein synthesis, cell growth and proliferation. However, when $4 \mathrm{E}-\mathrm{BP} 1$ is phosphorylated in response to upstream signals, the affinity of $4 \mathrm{E}-\mathrm{BP} 1$ binding to eIF4E is reduced; then eIF4E is released and cap-dependent translation can initiate, leading to relieve translational repression and enhancing cancerigenic protein synthesis $[26,27]$. Therefore, above data imply that the phosphorylation of $4 \mathrm{E}-\mathrm{BP} 1$ has carcinogenic potential and aggressive phenotype.

$4 \mathrm{E}-\mathrm{BP} 1$ can regulate the level of free eIF4E, which plays a crucial role in the regulation of translation and has a significant function in the translation of key proteins in tumor transformation, including Myc, cyclin D1, vascular endothelial growth factor, and fibroblastic growth factor [28]. A recent research on renal cell carcinoma has been shown that overexpression of 4E-BP1 and eIF4E synergistically promote progression of disease [17]. Avdulov et al. [29] have demonstrated that eIF4E is an important component of the malignant phenotype in breast cancer and hyperphosphorylation of $4 \mathrm{E}$ $\mathrm{BP} 1$ is vital in this effect. In their research, transfer of 4E-BP1 phosphorylation site mutants into breast cancer cell suppresses their carcinogenesis, while loss of these 4E-BP1 phosphorylation site mutants accompanies spontaneous reversion to a malignant phenotype. These results could be accounted for the fact that the phosphorylation of 4E-BP1 releases eIF4E and enhances cap-dependent translation, promoting tumor cell growth and proliferation.

We acknowledge that there are several limitations in this study. First, this was a retrospective study in a relatively short observation period, and the sample size of 164 patients in such a common disease like CRC was not large enough. Additional studies involving greater numbers of patients will be essential to confirm our findings. Second, this study consisted of patients with heterogeneous characteristics. Therefore, it is unclear whether present findings could be applied to all CRC patients stratified by major parameters. Third, we have not focused on the precise signal pathway by which p-4E-BP1 may promote the progression of CRC. Notwithstanding these limitations, this work provides a new insight for CRC prognosis prediction. Moreover, data from the current study indicate that p-4E-BP1 may function as a hallmark or funnel factor where upstream carcinogenic signals converge and dephosphorylation of 4E-BP1 could be an effective therapeutic method for CRC. Further studies of the signaling pathways that regulate 4E-BP1 phosphorylation may reveal additional therapeutic options to debilitate unrestricted protein biosynthesis in CRC.

In conclusion, the phosphorylation of $4 \mathrm{E}-\mathrm{BP} 1$ is important in CRC and high p-4E-BP1 level is associated with tumor progression and adverse prognosis. However, it is still uncertain how $\mathrm{p}-4 \mathrm{E}-\mathrm{BP} 1$ works in the carcinogenesis of CRC. Effective inhibition of the pathways responsible for 4E-BP1 phosphorylation might provide a new useful strategy for individualized therapy of CRC patients.

Acknowledgements: This work is supported by the grant from Wenzhou Municipal Science and Technology Bureau (Y20130231). 


\section{References}

[1] SIEGEL RL, MILLER KD, JEMAL A. Cancer statistics, 2015. CA Cancer J Clin 2015; 65: 5-29. https://doi.org/10.3322/ caac. 21254

[2] BRENNER H, KLOOR M, POX CP. Colorectal cancer. Lancet 2014; 383: 1490-1502. https://doi.org/10.1016/S01406736(13)61649-9

[3] EDWARDS MS, CHADDA SD, ZHAO Z, BARBER BL, SYKES DP. A systematic review of treatment guidelines for metastatic colorectal cancer. Colorectal Dis 2012; 14: e31-47. https://doi. org/10.1111/j.1463-1318.2011.02765.x

[4] HUBBARD JM, GROTHEY A. When less is more: maintenance therapy in colorectal cancer. Lancet 2015; 385: 1808-1810. https://doi.org/10.1016/S0140-6736(14)62350-3

[5] LIU Y, ZHANG X, HAN C, WAN G, HUANG X et al. TP53 loss creates therapeutic vulnerability in colorectal cancer. Nature 2015; 520: 697-701. https://doi.org/10.1038/nature 14418

[6] HANAHAN D, WEINBERG RA. Hallmarks of cancer: the next generation. Cell 2011; 144: 646-674. https://doi. org/10.1016/j.cell.2011.02.013

[7] CASTELLVI J, GARCIA A, RUIZ-MARCELLAN C, HERNANDEZ-LOSA J, PEG V et al. Cell signaling in endometrial carcinoma: phosphorylated 4E-binding protein-1 expression in endometrial cancer correlates with aggressive tumors and prognosis. Hum Pathol 2009; 40: 1418-1426. https://doi. org/10.1016/j.humpath.2008.12.019

[8] ROJO F, NAJERA L, LIROLA J, JIMENEZ J, GUZMAN $\mathrm{M}$ et al. 4E-binding protein 1, a cell signaling hallmark in breast cancer that correlates with pathologic grade and prognosis. Clin Cancer Res 2007; 13: 81-89. https://doi. org/10.1158/1078-0432.CCR-06-1560

[9] MAGAGNIN MG, VAN DEN BEUCKEN T, SERGEANT $\mathrm{K}$, LAMBIN P, KORITZINSKY $\mathrm{M}$ et al. The mTOR target 4E-BP1 contributes to differential protein expression during normoxia and hypoxia through changes in mRNA translation efficiency. Proteomics 2008; 8: 1019-1028. https://doi. org/10.1002/pmic.200700551

[10] BARNHART BC, LAM JC, YOUNG RM, HOUGHTON PJ, KEITH B et al. Effects of 4E-BP1 expression on hypoxic cell cycle inhibition and tumor cell proliferation and survival. Cancer Biol Ther 2008; 7: 1441-1449. https://doi.org/10.4161/ cbt.7.9.6426

[11] CHAO YK, CHUANG WY, YEH CJ, CHANG YS, WU YC et al. High phosphorylated 4E-binding protein 1 expression after chemoradiotherapy is a predictor for locoregional recurrence and worse survival in esophageal squamous cell carcinoma patients. J Surg Oncol 2012; 105: 288-292. https:// doi.org/10.1002/jso.22097

[12] KORKOLOPOULOU P, LEVIDOU G, EL-HABR EA, PIPERI $\mathrm{C}, \mathrm{ADAMOPOULOS} \mathrm{C}$ et al. Phosphorylated 4E-binding protein 1 (p-4E-BP1): a novel prognostic marker in human astrocytomas. Histopathology 2012; 61: 293-305. https://doi. org/10.1111/j.1365-2559.2012.04236.x

[13] NISHIKAWA M, MIYAKE H, HARADA K, FUJISAWA M. Expression of molecular markers associated with the mam- malian target of rapamycin pathway in nonmetastatic renal cell carcinoma: Effect on prognostic outcomes following radical nephrectomy. Urol Oncol 2014; 32: 49.e15-21. https:// doi.org/10.1016/j.urolonc.2013.07.014

[14] FANG Z, LU L, TIAN Z, LUO K. Overexpression of phosphorylated $4 \mathrm{E}$-binding protein 1 predicts lymph node metastasis and poor prognosis of Chinese patients with hilar cholangiocarcinoma. Med Oncol 2014; 31: 940. https://doi.org/10.1007/ s12032-014-0940-5

[15] ROH MS, LEE JH, KANG KW, NAM HY, JUNG SB et al. Phosphorylated 4E-binding protein 1 expression is associated with poor prognosis in small-cell lung cancer. Virchows Arch 2015; 467: 667-673. https://doi.org/10.1007/s00428-015$\underline{1860-2}$

[16] LEE HW, LEE EH, LEE JH, KIM JE, KIM SH et al. Prognostic significance of phosphorylated 4E-binding protein 1 in non-small cell lung cancer. Int J Clin Exp Pathol 2015; 8: 3955-3962.

[17] CAMPBELL L, JASANI B, GRIFFITHS DF, GUMBLETON M. Phospho-4e-BP1 and eIF4E overexpression synergistically drives disease progression in clinically confined clear cell renal cell carcinoma. Am J Cancer Res 2015; 5: 2838-2848.

[18] EDGE SB, BYRD DR, COMPTON CC, FRITZ AG, GREENE FL et al. 14. Colon and rectum, p. 143-146. In. SB. Edge, DR. Byrd, M. Carducci, CC. Compton, AG. Fritz (Eds.), AJCC cancer staging manual, 7th Edition. New York, Springer-Verlag, 2010, pp 648. ISBN 9780387884400.

[19] BENAVENTE S, VERGES R, HERMOSILLA E, FUMANAL $\mathrm{V}$, CASANOVA $\mathrm{N}$ et al. Overexpression of phosphorylated $4 \mathrm{E}-\mathrm{BP} 1$ predicts for tumor recurrence and reduced survival in cervical carcinoma treated with postoperative radiotherapy. Int J Radiat Oncol Biol Phys 2009; 75: 1316-1322. https://doi. org/10.1016/j.ijrobp.2009.01.004

[20] SINICROPE FA, SHI Q. Combining molecular markers with the TNM staging system to improve prognostication in stage II and III colon cancer: are we ready yet? J Natl Cancer Inst 2012; 104: 1616-1618. https://doi.org/10.1093/ jnci/djs 441

[21] MCMAHON BJ, KWAAN HC. Components of the Plasminogen-Plasmin System as Biologic Markers for Cancer. Adv Exp Med Biol 2015; 867: 145-156. https://doi.org/10.1007/978-94017-7215-0 10

[22] WATSON MM, SOREIDE K. The prognostic yield of biomarkers harvested in chemotherapy-naive stage II colon cancer: can we separate the wheat from the chaff? Mol Med 2016; 22: 271-273.

[23] KOLCH W. Coordinating ERK/MAPK signalling through scaffolds and inhibitors. Nat Rev Mol Cell Biol 2005; 6: 827-837. https://doi.org/10.1038/nrm1743

[24] SHE QB, HALILOVIC E, YE Q, ZHEN W, SHIRASAWA $S$ et al. 4E-BP1 is a key effector of the oncogenic activation of the AKT and ERK signaling pathways that integrates their function in tumors. Cancer Cell 2010; 18: 39-51. https://doi. org/10.1016/j.ccr.2010.05.023

[25] WANG J, YE Q, SHE QB. New insights into 4E-BP1-regulated translation in cancer progression and metastasis. Cancer Cell Microenviron 2014; 5: pii: e331. 
[26] ARMENGOL G, ROJO F, CASTELLVI J, IGLESIAS C, CUATRECASAS $\mathrm{M}$ et al. 4E-binding protein 1: a key molecular "funnel factor" in human cancer with clinical implications. Cancer Res 2007; 67: 7551-7555. https://doi. org/10.1158/0008-5472.CAN-07-0881

[27] AVEROUS J, PROUD CG. When translation meets transformation: the mTOR story. Oncogene 2006; 25: 6423-6435. https://doi.org/10.1038/sj.onc.1209887
[28] RICHTER JD, SONENBERG N. Regulation of cap-dependent translation by eIF4E inhibitory proteins. Nature 2005; 433: 477-480. https://doi.org/10.1038/nature03205

[29] AVDULOV S, LI S, MICHALEK V, BURRICHTER D, PETERSON M et al. Activation of translation complex eIF4F is essential for the genesis and maintenance of the malignant phenotype in human mammary epithelial cells. Cancer Cell 2004; 5: 553-563. https://doi.org/10.1016/j.ccr.2004.05.024 